\title{
Survival Analysis of Gastric Cancer Patients Using Illness-Death Model In Kerman City, Southeast Iran during 2001-2016
}

\author{
Touba Narimani Moghadam 1,2, Moghaddameh Mirzaee ${ }^{1,2, *}$, Abbas Bahrampour ${ }^{1,2}$, \\ Yunes Jahani ${ }^{1,2}$, Mehdi Hayatbakhsh Abbasi ${ }^{3}$
}

1. Modeling in Health Research Center, Institute for Futures Studies in Health, Kerman University of Medical Sciences, Kerman, Iran

2. Department of Biostatistics and Epidemiology, School of Public Health, Kerman University of Medical Sciences, Kerman, Iran

3. Department of Gastroenterology, Afzalipour Hospital, Kerman University of Medical Sciences, Kerman, Iran

\section{* Corresponding Author:}

Moghaddameh Mirzaee, MD Modeling in Health Research Center, Institute for Futures Studies in Health, Kerman University of Medical Sciences, Kerman, Iran

Telefax: + 983431325808

Email: m_mirzaee@kmu.ac.ir

Received: 05 Dec. 2020

Accepted: 03 May 2021

\section{ABSTRACT}

\section{BACKGROUND}

Gastric cancer (GC) is the fifth most common cancer and the third most common cause of cancer death worldwide. The aim of this study was to investigate the factors affecting the survival of patients with GC using the illness-death model (metastasis as an intermediate event).

\section{METHODS}

In this retrospective cohort study, 339 patients with GC who were referred to Shahid Bahonar and Afzalipour Hospitals in Kerman, Southeast Iran during 2001-2016 were included. Demographic, therapeutic, and clinical data were collected from the patients' medical records. To evaluate the factors affecting patients' survival and the relationship between the factors, the illness-death model (metastasis as an intermediate event) was used.

\section{RESULTS}

One, three, and five-year survival rates in patients with GC were estimated to be $63 \%$, $40 \%$, and $30 \%$, respectively. The results of analysis of illness-death model showed that age $(\mathrm{HR}=0.98,95 \% \mathrm{CI}: 0.97-0.99 ; p=0.007)$ and histological grade $(\mathrm{HR}=1.77 ; 95 \%$ CI: $1.68-2.67 ; \mathrm{p}=0.007)$ affected metastasis whereas history of cigarette smoking $(\mathrm{HR}=$ $1.89 ; 95 \% \mathrm{CI}: 1.08-3.3 ; p=0.02)$ and chemotherapy (HR=0.63; 95\% CI: $0.4-0.93 ; p=$ $0.02)$ affected death hazard without metastasis. History of opium use $(\mathrm{HR}=2.11 ; 95 \% \mathrm{CI}$ : 1.17- 3.8; $p=0.002)$, family history of GC (HR $=2.48 ; 95 \% \mathrm{CI}: 1.2-5.15 ; p=0.01)$ and histological grade $(\mathrm{HR}=1.85 ; 95 \% \mathrm{CI}: 1.11-3.08 ; p=0.02)$ were identified as factors affecting death hazard in patients with metastasis.

\section{CONCLUSION}

According to the results, patients' age at the time of diagnosis and histological grade have a significant effect on the occurrence of metastasis. In addition, using the diseasedeath model, a complete understanding of the behavior and effects of the studied variables on different disease states can be realized.

\section{KEYWORDS:}

Gastric cancer, Intermediate events, Illness-death model, Survival analysis, Iran

Please cite this paper as:

Narimani Moghadam T, Mirzaee M, Bahrampour A, Jahani Y, Hayatbakhsh Abbasi M. Survival Analysis of Gastric Cancer Patients Using Illness-Death Model in Kerman City, Southeast Iran during 2001-2016. Middle East J Dig Dis 2021;13:207-214. doi: 10.34172/mejdd.2021. 227. 


\section{INTRODUCTION}

Gastric cancer (GC) is the fifth most common cancer and the third leading cause of cancer death worldwide. The International Agency for Research on Cancer (IARC) announced that the standardized incidence rate of GC was $11.1 \%$ per 100,000 people in 2018 . The highest standardized incidence rate of GC was found in East Asia (22.4\% per 100,000 people). In this area, the highest mortality rate of GC was $15.9 \%$ per 100,000 people. In Iran, GC was the most common cancer in men $(21.6 \%$ per 100,000 people) and the second most commonly reported cancer in women $(9.8 \%$ per 100,000$)$ after breast cancer. ${ }^{1}$ Due to the limitations of diagnostic techniques for the diagnosis of GC in the early stages, the disease is diagnosed in the advanced stages or after metastasis. ${ }^{2,3}$ In the early stages of GC, surgery is used, and, if necessary, chemotherapy and radiotherapy are used for the treatment. In the advanced stages, all three treatment methods are used, but because of disease progression, they have no significant effect on the patients' survival. ${ }^{2,4}$ Metastasis is one of the prognostic factors that reduces the survival of patients with GC. The survival rate of patients with metastasis is less than that of patients without metastasis. ${ }^{5}$ The survival rate of patients with GC varies from country to country. The 5 -year survival rate of patients with metastasis in South Korea and Iran was 20.8 and $0.06 \%$, respectively. ${ }^{5,6}$ Sometimes in clinical studies of cancer, more than one endpoint can be defined; for example, in breast cancer, the final endpoints can be defined as recovery, disease recurrence, metastasis, or death. The analysis of endpoints in classical survival is done separately, which is not useful, because it does not consider the relationships between possible events and endpoints. ${ }^{7}$ To solve this problem, multi-state models (MSMs) can be used. These models are based on a continuous random process that allows individuals to move through a limited number of states, including recovery, disease recurrence, metastasis, or death. ${ }^{78}$ The illness-death model (disability) is one of the varieties of MSMs, which is the generalization of the competitive hazard models. ${ }^{9}$ This model is used to examine the progression of chronic diseases and investigates the effects of intermediate events in medical research. ${ }^{10}$ Regarding intermediate events, MSMs provide a detailed description of the progression of the disease. On the other hand, these models help cancer researchers identify factors affecting the incidence of these events. ${ }^{4}$ A study was conducted by Von Cube and colleagues (2017) on the MSMs in the United States, which reported that these models were identified as the first useful steps in a comprehensive review of complex data. ${ }^{11}$ Other studies in the Netherlands and Iran showed that these models were useful in predicting the process and modeling the disease., ${ }^{72}$ To our knowledge, there is no study on the effect of metastasis on death, as a moderate event, in Iran. Therefore, in this study we aimed to evaluate the effect of different factors on the hazard of transfer between different disease states, considering metastasis as an intermediate event, using illness-death model in patients with GC in Kerman city, southeast Iran.

\section{MATERIALS AND METHODS}

\section{Study population}

In this retrospective cohort study, 339 patients with GC who were referred to Bahonar and Afzalipour Hospitals in Kerman city from 2001 to 2016 were examined. Demographic and clinical data were extracted from patients' medical records. Patients' survival status was recorded through patients' medical records or telephone calls. The studied variables included age (year), sex, history of smoking (cigarette, opium, cigarette+opium, none), place of residence (rural and urban areas), family history of gastric cancer, therapeutic characteristics (surgery, chemotherapy, and radiotherapy), clinical features including histological grade (well, moderate, poor), and type of pathology (adenocarcinoma, and others). The time (month) from diagnosis to death or metastasis, as well as from metastasis to death, was considered as response variables.

\section{Statistical Analysis}

Multi-state models (MSMs) include one or more starting, intermediate, and absorbing states. Patients, in a particular period of follow-up, can be only in one of these states, and in the case of any event, the patients' state changes to another state, which is called transition. In the case of no event, patients will remain in their state. ${ }^{13}$ In this study, a three-state model (disease-metastasis-death) using semiparametric Cox model and Markov assumption with three states of disease (state 1), metastasis (state 2), and death (state 3 ) was used. The factors affecting the hazard of transition between states (state $1 \rightarrow$ state 3 ), (state $1 \rightarrow$ state 2 ), and 
Table 1: Patient Demographics and Clinical Characteristics

\begin{tabular}{|c|c|c|c|}
\hline Prognostic factors & & N (\%) & $\begin{array}{l}\text { Median of } \\
\text { survival time } \\
\text { (months) }\end{array}$ \\
\hline \multirow{2}{*}{ Sex } & Male & $216(63.7)$ & 25.5 \\
\hline & Female & $123(36.3)$ & 24.5 \\
\hline \multirow{2}{*}{ Place of residence } & Urban & $272(80.2)$ & 24.4 \\
\hline & Rural & $67(19.8)$ & 36.6 \\
\hline \multirow{4}{*}{$\begin{array}{l}\text { History of smok- } \\
\text { ing }\end{array}$} & Cigarette & $31(9.1)$ & 21.2 \\
\hline & Opium & 64 (18.9) & 17.3 \\
\hline & $\begin{array}{l}\text { Cigarette }+ \\
\text { Opium }\end{array}$ & $60(17.7)$ & 19.8 \\
\hline & None & $184(54.3)$ & 26.3 \\
\hline \multirow{2}{*}{ Surgery } & Yes & $274(80.8)$ & 26.1 \\
\hline & No & $65(19.2)$ & 21.2 \\
\hline \multirow{2}{*}{ Chemotherapy } & Yes & $135(39.8)$ & 27.4 \\
\hline & No & $204(60.2)$ & 19.6 \\
\hline \multirow{2}{*}{ Radiotherapy } & Yes & $46(13.6)$ & 35 \\
\hline & No & $293(86.4)$ & 22.6 \\
\hline \multirow{2}{*}{$\begin{array}{l}\text { Family history } \\
\text { of GC }\end{array}$} & Yes & $29(8.6)$ & 23 \\
\hline & No & $310(91.4)$ & 25.5 \\
\hline \multirow{3}{*}{ Histological grade } & Well (G1) & $11(3.2)$ & 35.8 \\
\hline & $\begin{array}{l}\text { Moderate } \\
\text { (G2) }\end{array}$ & $270(79.6)$ & 26.7 \\
\hline & Poor (G3) & $58(17.1)$ & 17.1 \\
\hline \multirow[b]{2}{*}{ Morphology } & Other & $58(17.1)$ & 27.4 \\
\hline & $\begin{array}{l}\text { Adenocar- } \\
\text { cinoma }\end{array}$ & $281(82.9)$ & 23 \\
\hline \multirow{2}{*}{ Metastasis } & Yes & $117(34.5)$ & 19.6 \\
\hline & No & $222(65.5)$ & 27.6 \\
\hline
\end{tabular}

(state $2 \rightarrow$ state 3 ) were investigated.

According to the Markov assumption, the hazard of transition to the next state depends only on the current state of the patient and does not depend on the elapsed time ${ }^{14}$ (figure 1).

The following function represents the hazard rates (or transition intensity rates) for moving from state $\mathrm{h}$ to state $\mathrm{j}$ at times $\mathrm{t}$ and is defined as below:

$\mathrm{a}_{\mathrm{hj}}(\mathrm{t})=\lim _{(\Delta t \rightarrow \mathrm{t})} 1 / \Delta \mathrm{t} \mathrm{p}$ (patients move from stateh to state $\mathrm{j}$ in $(\mathrm{t} . \mathrm{t}+\Delta \mathrm{t} \mid \mathrm{h}$ at $\mathrm{t}))^{15}$

To determine the important prognostic factors, the univariate Cox model was used for each transition, considering the significant level of $20 \%$. Then these variables entered into the multi-state model. Finally, by using software R 3.5.1, mstate and msm packages, and backward method important variables affecting the hazard of transition between
Table 2: Summary of the Number of Transitions for each State

\begin{tabular}{lcccc}
\hline State & $\begin{array}{c}\text { N to } \\
\text { enter }\end{array}$ & $\mathbf{3}$ (Death) & 2 (Metastasis) & 1(Disease) \\
\hline 1 (Disease) & 339 & $99(29.2)$ & $117(34.5)$ & $123(36.3)$ \\
\hline 2 (Metastasis) & 117 & - & $43(36.8)$ & $74(63.2)$ \\
\hline 3 (Death) & 197 & - & - & - \\
\hline
\end{tabular}

different states were significant at level 0.05 remained in the model. This study was approved by the Ethics Committee of Kerman University of Medical Sciences (ethics code: IR.KMU.REC.1397.175).

\section{RESULTS}

In this study, 339 patients with $\mathrm{GC}$ with a mean age of $62.84 \pm 14.53$ years (range: $21-90$ years) at the time of diagnosis were included. Of these patients, $216(63.7 \%)$ were male, $272(80.2 \%)$ were urban residents, 31 (9.1\%) had a history of cigarette smoking, and 64 (18.9\%) had a history of opium use. The highest median survival rate belonged to rural patients, and the lowest one belonged to those with poor-grade tumors (table1).

The one, three, and five-year survival of patients with GC was $63 \%, 40 \%$, and 30\%, respectively. According to the Kaplan-Meier estimator, about $50 \%$ of the patients survived for 2 years or more (figure 2).

Table 2 summarizes the disease, metastasis, and death states. Of 339 patients with GC, 117 patients experienced metastasis (transition 1), 123 died (transition 2), and the rest remained in the same state. Of 117 patients with metastasis in state 2, 74 died (transition 3), and 43 remained in the metastasis state.

The effect of different variables on the hazard of death without metastasis, the hazard of death with metastasis, and the hazard of metastasis are shown in table 3. The patients' age at the time of diagnosis and tumor grade were the factors affecting the occurrence of metastasis (transition 1), and accordingly, the hazard of metastasis in patients with poor-grade tumor was 1.77 times higher than that in patients with moderate-grade tumor $(\mathrm{HR}=1.77$; 95\% CI: $1.68-2.67 ; p=0.007)$. Also, the hazard of metastasis was reduced to 0.02 with the increase of each year of the age of the patients ( $\mathrm{HR}=0.98,95 \% \mathrm{CI}: 0.97-0.99 ; p=0.007)$. Regarding the factors affecting the hazard of transition 2 (the hazard of death without metastasis), the variables 


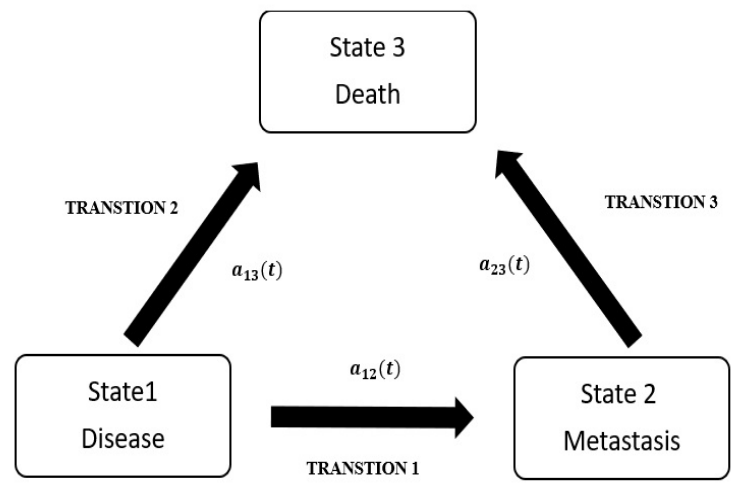

Fig. 1: Illness-death model for Gastric Cancer

of cigarette smoking and chemotherapy were statistically significant.

The hazard of death for cigarette smokers was 1.89 times higher than those without a history of cigarette smoking ( $\mathrm{HR}=1.89 ; 95 \% \mathrm{CI}: 1.08-3.3 ; p=0.02)$. Also, the hazard of death in patients who underwent chemotherapy was 0.63 less than that in those who did not receive chemotherapy, indicating that the hazard of death was reduced by about $37 \%$ in these patients ( $\mathrm{HR}=0.63 ; 95 \%$ CI: $0.4-0.93 ; p=0.02$ ). In addition, opium use, familial history of gastric cancer, and tumor grade were the factors affecting the hazard of death in transition 3 (metastasis to death). The hazard of death in patients with metastasis and history of opium use was 2.11 times higher than that in those without a history of use opium $(\mathrm{HR}=2.11 ; 95 \% \mathrm{CI}$ : $1.17-3.8 ; p=0.002$ ). Also, the hazard of death in patients with a family history of GC was 2.48 times higher than that in those without a family history of gastric cancer (HR $=2.48 ; 95 \%$ CI: $1.2-5.15 ; p=0.01)$. The hazard of death in patients with poor-grade tumors was 1.85 times higher than that in those with moderate-grade tumors (HR $=1.85 ; 95 \%$ CI: $1.11-3.08 ; p=0.02$ ).

Figure 3 shows the transition probabilities for death and metastasis. The probability of metastasis increased by 20 months after diagnosis, and its maximum rate was $37 \%$ on the 20th month. From month 20 to 50, the slope of the probability of metastasis was slightly declined and fixed after the 50th month. The hazard of death had an increasing trend, and the maximum rate was $90 \%$ on the 100 th month after diagnosis.

\section{DISCUSSION}

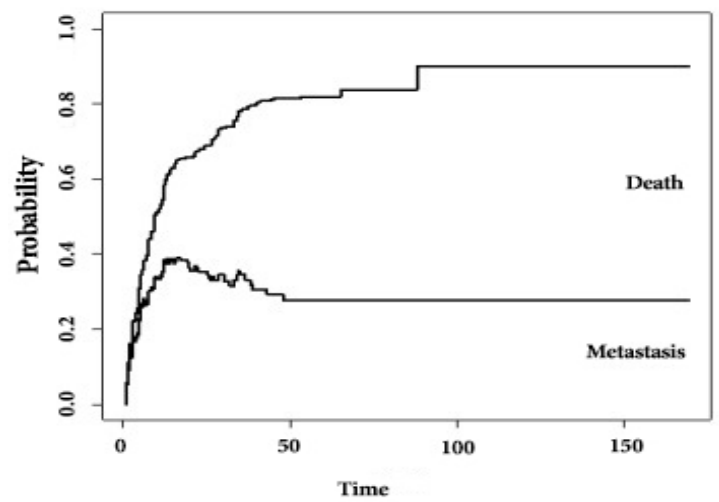

Fig. 2: The transition probabilities for each event

In this study, the 5-year survival rate in patients with $\mathrm{GC}$ was $30 \%$, which is relatively consistent with the results of a study by Roshanaei and colleagues (2011) in Iran $(26 \%) .{ }^{16}$ However, the 5-year survival rate in Japan and South Korea was reported 54-58\%. ${ }^{17}$ The discrepancy between the obtained results and those reported in developed countries can be due to the fact that in Iran, patients usually refer to physicians in the advanced stages of the disease; therefore, the treatments employed at this stage have less effect on the patients' survival rate. In fact, early and timely diagnosis of the disease can improve the patients' survival rate. Most studies have used survival standard models to identify factors affecting the survival rate of patients with GC. ${ }^{16,18}$ These models focus only on identifying factors affecting the time of death, ${ }^{4}$ while MSMs provide a better understanding of the disease process and its associated risk factors. ${ }^{19}$ In other words, using these models, the indirect effects of variables on the patients' survival can be investigated. 4,5

In the present study, metastasis was considered as an intermediate state, which can be used to identify factors affecting the survival of patients with $\mathrm{GC}$ indirectly. According to the results, chemotherapy and cigarette smoking had a direct effect on the patients' survival, while the degree of tumor differentiation and patients' age had an indirect effect on the survival of patients. In other words, these variables were effective on the incidence of metastasis. In patients with metastasis, factors such as the family history of GC, degree of tumor differentiation, and opium use had an effect on the patients' survival.

According to the results of the present study, the patients' age at the time of diagnosis was one of the factors affecting 
Table 3: Estimated effects in Cox models for each transition

\begin{tabular}{|c|c|c|c|c|c|c|c|}
\hline & & \multicolumn{2}{|c|}{ State $1 \rightarrow 2$} & \multicolumn{2}{|c|}{ State $1 \rightarrow 3$} & \multicolumn{2}{|c|}{ State $2 \rightarrow 3$} \\
\hline Variables & & $\begin{array}{c}\text { Crude } \\
\text { HR CI9) } \\
p \text {-value }\end{array}$ & $\begin{array}{c}\text { Adjusted } \\
\mathrm{HR}, \mathrm{CI} 95 \% \\
p \text {-value }\end{array}$ & $\begin{array}{c}\text { Crude } \\
\text { HR, CI95\% } \\
p \text {-value }\end{array}$ & $\begin{array}{c}\text { Adjusted } \\
\text { HR, CI95\% } \\
p \text {-value }\end{array}$ & $\begin{array}{c}\text { Crude } \\
\text { HR, } \\
\text { CI95\% } \\
p \text {-value }\end{array}$ & $\begin{array}{c}\text { Adjusted } \\
\text { HR, CI95\% } \\
p \text {-value }\end{array}$ \\
\hline Age & & $\begin{array}{c}0.98(0.97- \\
0.99) \\
0.004\end{array}$ & $\begin{array}{c}0.98(0.97- \\
0.99) \\
0.007\end{array}$ & $\begin{array}{c}1.01(0.99- \\
1.02) \\
0.29\end{array}$ & $\begin{array}{c}1.01(0.99- \\
1.02) \\
0.25\end{array}$ & $\begin{array}{c}0.99(0.98- \\
1.01) \\
0.35\end{array}$ & $\begin{array}{l}1(0.98-1.02) \\
0.85\end{array}$ \\
\hline Sex (ref: male) & Female & $\begin{array}{c}1.5(0.59- \\
1.28) \\
0.48\end{array}$ & $\begin{array}{c}0.7(0.45-1.08) \\
0.11\end{array}$ & $\begin{array}{c}1.22(0.85- \\
1.75) \\
0.28\end{array}$ & $\begin{array}{c}1.48(0.96- \\
2.29) \\
0.07\end{array}$ & $\begin{array}{c}1.04(0.6- \\
1.56) \\
0.87\end{array}$ & $\begin{array}{c}0.95(0.51- \\
1.78) \\
0.88\end{array}$ \\
\hline $\begin{array}{l}\text { Place of residence } \\
\text { (ref: urban) }\end{array}$ & Rural & $\begin{array}{c}0.9(0.71- \\
1.72) \\
0.63\end{array}$ & $\begin{array}{c}1.01(0.65- \\
1.58) \\
0.95\end{array}$ & $\begin{array}{c}0.7(0.43- \\
1.32) \\
0.15\end{array}$ & $\begin{array}{c}0.76(0.46- \\
1.24) \\
0.27\end{array}$ & $\begin{array}{c}1.15(0.94- \\
1.53) \\
0.62\end{array}$ & $\begin{array}{c}1.14(0.61- \\
2.12) \\
0.67\end{array}$ \\
\hline \multirow{3}{*}{$\begin{array}{l}\text { History of smoking } \\
\text { (ref: None) }\end{array}$} & $\begin{array}{l}\text { Ciga- } \\
\text { rette }\end{array}$ & $\begin{array}{c}0.73(0.35- \\
1.51) \\
0.39\end{array}$ & $\begin{array}{c}0.82(0.38- \\
1.76) \\
0.61\end{array}$ & $\begin{array}{c}1.99(1.14- \\
3.48) \\
0.01\end{array}$ & $\begin{array}{c}1.89(1.08- \\
3.3) \\
0.02\end{array}$ & $\begin{array}{c}0.29(0.07- \\
1.2) \\
0.09\end{array}$ & $\begin{array}{c}0.36(0.08- \\
1.53) \\
0.17\end{array}$ \\
\hline & Opium & $\begin{array}{c}0.88(0.54- \\
1.44) \\
0.62\end{array}$ & $\begin{array}{c}0.91(0.55- \\
1.50) \\
0.71\end{array}$ & $\begin{array}{c}1(0.61- \\
1.64) \\
0.97\end{array}$ & $\begin{array}{c}1.07(0.65- \\
1.77) \\
0.78\end{array}$ & $\begin{array}{c}2.11(1.21- \\
3.68) \\
0.008\end{array}$ & $\begin{array}{c}2.11(1.17-3.8) \\
0.002\end{array}$ \\
\hline & $\begin{array}{l}\text { Ciga- } \\
\text { rette }+ \\
\text { Opium }\end{array}$ & $\begin{array}{c}0.97(0.59- \\
1.58) \\
0.9\end{array}$ & $\begin{array}{c}0.81(0.47- \\
1.39) \\
0.45\end{array}$ & $\begin{array}{c}1.04(0.64- \\
1.7) \\
0.85\end{array}$ & $\begin{array}{c}1.33(0.76- \\
2.33) \\
0.32\end{array}$ & $\begin{array}{c}1.04(0.56- \\
1.94) \\
0.9\end{array}$ & $\begin{array}{c}1.08(0.58- \\
2.04) \\
0.79\end{array}$ \\
\hline Surgery (ref: Yes) & No & $\begin{array}{c}1.03(0.64- \\
1.67) \\
0.9\end{array}$ & $\begin{array}{c}0.81(0.55- \\
1.51) \\
0.72\end{array}$ & $\begin{array}{c}0.72(0.47- \\
1.09) \\
0.1\end{array}$ & $\begin{array}{c}0.84(0.54- \\
1.33) \\
0.46\end{array}$ & $\begin{array}{c}1.09(0.49- \\
1.69) \\
0.76\end{array}$ & $\begin{array}{c}0.97(0.48- \\
1.96) \\
0.94\end{array}$ \\
\hline $\begin{array}{l}\text { Chemotherapy } \\
\text { (ref: No) }\end{array}$ & Yes & $\begin{array}{c}1.47(1.02- \\
2.12) \\
0.04\end{array}$ & $\begin{array}{c}1.47(0.97- \\
2.22) \\
0.07\end{array}$ & $\begin{array}{c}0.61(0.42- \\
0.9) \\
0.01\end{array}$ & $\begin{array}{c}0.63(0.4- \\
0.93) \\
0.02\end{array}$ & $\begin{array}{c}0.94(0.6- \\
2.04) \\
0.8\end{array}$ & $\begin{array}{c}0.77(0.44- \\
1.36) \\
0.37\end{array}$ \\
\hline $\begin{array}{l}\text { Radiotherapy } \\
\text { (ref: No) }\end{array}$ & Yes & $\begin{array}{c}1.1(0.68- \\
1.78) \\
0.69\end{array}$ & $\begin{array}{c}0.75(0.43- \\
1.31) \\
0.32\end{array}$ & $\begin{array}{c}0.61(0.35- \\
1.07) \\
0.09\end{array}$ & $\begin{array}{c}0.78(0.4- \\
1.53) \\
0.48\end{array}$ & $\begin{array}{c}1.42(0.79- \\
2.55) \\
0.24\end{array}$ & $\begin{array}{c}1.07(0.46- \\
2.51) \\
0.87\end{array}$ \\
\hline $\begin{array}{l}\text { Family history } \\
\text { (ref: No) }\end{array}$ & Yes & $\begin{array}{c}1.09(0.59- \\
1.97) \\
0.79\end{array}$ & $\begin{array}{c}0.88(0.48- \\
1.63) \\
0.69\end{array}$ & $\begin{array}{c}0.88(0.46- \\
1.67) \\
0.89\end{array}$ & $\begin{array}{c}1.1(0.56- \\
2.2) \\
0.95\end{array}$ & $\begin{array}{c}2.76(1.36- \\
5.59) \\
0.005\end{array}$ & $\begin{array}{c}2.48(1.2-5.15) \\
0.01\end{array}$ \\
\hline \multirow{2}{*}{$\begin{array}{l}\text { Histological grade } \\
\text { (ref: G2) }\end{array}$} & Well & $\begin{array}{c}0.47(0.11- \\
1.91) \\
0.29\end{array}$ & $\begin{array}{c}0.49(0.11- \\
1.97) \\
0.31\end{array}$ & $\begin{array}{c}0.41(0.24- \\
1.78) \\
0.41\end{array}$ & $\begin{array}{c}0.84(0.3- \\
2.33) \\
0.73\end{array}$ & $\begin{array}{c}3.4(0.81- \\
14.26) \\
0.09\end{array}$ & $\begin{array}{c}1.83(0.41- \\
8.24) \\
0.43\end{array}$ \\
\hline & Poor & $\begin{array}{c}1.84(1.21- \\
2.77) \\
0.004\end{array}$ & $\begin{array}{c}1.77(1.68- \\
2.67) \\
0.007\end{array}$ & $\begin{array}{c}0.76(0.44- \\
1.3) \\
0.32\end{array}$ & $\begin{array}{c}0.8(0.46- \\
1.4) \\
0.45\end{array}$ & $\begin{array}{c}2.19(1.32- \\
3.62) \\
0.002\end{array}$ & $\begin{array}{c}1.85(1.11- \\
3.08) \\
0.02\end{array}$ \\
\hline $\begin{array}{l}\text { Morphology } \\
\text { (ref: other) }\end{array}$ & Other & $\begin{array}{c}1.24(0.8- \\
1.93) \\
0.34\end{array}$ & $\begin{array}{c}1.15(0.9-1.75) \\
0.38\end{array}$ & $\begin{array}{c}0.81(0.5- \\
1.31) \\
0.4\end{array}$ & $\begin{array}{c}0.95(0.59- \\
1.68) \\
0.31\end{array}$ & $\begin{array}{c}0.92(0.52- \\
1.62) \\
0.76\end{array}$ & $\begin{array}{c}0.88(0.5-1.45) \\
0.31\end{array}$ \\
\hline
\end{tabular}

Abbreviation: N.S: non-significant: $p$-value $>0.05$

metastasis, so that with the increase of age at diagnosis, the hazard of metastasis decreased. In this study, patients with metastasis were mostly young adults who were referred to a physician in the advanced stages of the disease when other parts of the body are involved by metastasis. Therefore, paying more attention and providing care to patients with cancer at lower ages of metastasis and timely diagnosis are very important. A study on patients with GC 
based on the standard survival models showed that with the increase of age, patients' survival was reduced. ${ }^{18}$ However, in the present study, analysis of the MSMs revealed that age had no direct effect on the patients' survival, and it had an indirect effect due to the occurrence of metastasis. However, this variable had no significant effect on the hazard of death without metastasis. Other studies in the United States and China also investigated the effect of this factor on patients with metastasis and showed that the hazard of metastasis in young adults was higher than that in older people. ${ }^{20,21}$ The findings of this study showed that the degree of tumor differentiation affected the hazard of metastasis and death with metastasis so that the hazard of death and metastasis in patients with poor-grade tumors was higher than that in those with moderate-grade tumors. This could be due to more malignant and dangerous cases and delayed diagnosis of the disease. The results of a study conducted in Iran using a standard survival model showed that tumor grade reduced the patients' survival, ${ }^{16}$ which is consistent with the results of a study conducted in the United States on patients with metastasis. ${ }^{22}$ In the present study, chemotherapy was directly associated with increased survival of patients without metastasis. This relationship can be attributed to the better physical condition of these patients without metastasis, and their treatment was effective. Conversely, the results of a study by Samadi et al (2011) in Ardabil province, Iran, showed that there was no significant relationship between this factor and the patients' survival rate. In this city, upper gastrointestinal cancer is the most common cancer and the cause of more than $50 \%$ of deaths, because patients refer to physicians in the advanced stages of the disease, therefore, the treatment of patients may not be effective. ${ }^{23}$ Other studies showed that chemotherapy increased patients' survival. ${ }^{24,25}$ The present study showed that cigaret te smoking increased the hazard of death in patients without metastasis. Several studies have shown that cigarette smoking reduces the survival of patients with GC. Also, evidence indicates that cigarette smoking is a risk factor for GC. ${ }^{26}$ The results of a study conducted in Iran using the standard survival model showed that smokers are more at the hazard of death compared with non-smokers. ${ }^{23}$ On the other hand, a study in Japan showed that patients with a history of cigarette smok- ing were directly at the hazard of death after surgery. ${ }^{26}$ The cause of reduced survival rate in smokers can be due to health behaviors, biological effects of cigarette smoking, and its non-genotoxic (epigenetic) effect, and genetic toxicity on tumor differentiation. ${ }^{27}$ It was also revealed that the family history of GC in patients with metastasis had a significant relationship with the increased hazard of death, which is consistent with the results of previous studies in Iran and other countries. ${ }^{28,29}$ Conversely, a study in Korea showed that family history of GC was associated with a reduced hazard of death. ${ }^{30}$ This discrepancy can be attributed to the attitude and health behavior change of these patients so that patients with a family history of GC are more likely to be controlled and treated because of their concern. ${ }^{30}$ Opium is traditionally used in Iran and other Eastern Mediterranean countries. These areas have the highest incidence rate of GC and death in the world. ${ }^{31}$ According to the results of this study, the opium use in patients with metastasis was associated with a reduction in the patients' survival rate. The high consumption of opium in Iran, especially in Kerman, may be due to having contentious border with Afghanistan, as the most important opium producer in the world, which makes opium easy to access. ${ }^{32}$ Conversely, the results of the study in Iran using the Frailty model showed no significant relationship between opium use and survival rate. ${ }^{33}$

The limitations of the present study were incomplete information and a low sample size. On the other hand, the strength of this study is the results obtained using MSMs. According to the results, some variables, such as patients' age and degree of tumor differentiation through the intermediate event (metastasis), indirectly affect the survival of patients, while in previous studies using standard models, these variables directly affected the patients' survival. In other words, using MSMs, a complete understanding of the behavior and effects of the studied variables on the patients' survival in different transitions can be provided.

\section{CONCLUSION}

According to the results obtained using the illnessdeath model, the degree of tumor differentiation and patients' age had a significant effect on the hazard of metastasis. Also, family history of gastric cancer, opium use, and degree of tumor differentiation in pa- 
tients with metastasis had an effect on the hazard of death. Chemotherapy and cigarette smoking had a direct effect on the hazard of death. In addition, using the disease-death model, a complete understanding of the behavior and effects of the studied variables on different disease states can be realized.

\section{Funding}

This study was a part of an MSc thesis by Touba Narimani Moghadam, supported by Kerman University of Medical Sciences.

\section{ACKNOWLEDGMENTS}

The author would like to gratitude Kerman University of Medical Sciences that supported this study.

\section{ETHICAL APPROVAL}

There is nothing to be declared.

\section{CONFLICT OF INTEREST}

The authors declare no conflict of interest related to this work.

\section{REFERENCES}

1. WHO. International Agency for Research on Cancer. Source: Globocan, http://gcoiarcfr/today/fact-sheetscancers. 2018

2. Kangi AK, Bahrampour A. Predicting the Survival of Gastric Cancer Patients Using Artificial and Bayesian Neural Networks. Asian Pac J Cancer Prev 2018;19:487-90. doi: 10.22034/APJCP.2018.19.2.487.

3. Lin MT, Song HJ, Ding XY. Long non-coding RNAs involved in metastasis of gastric cancer. World J Gastroenterol 2018;24:3724-37. doi: 10.3748/wjg.v24.i33.3724.

4. Zare A, Mahmoodi M, Mohammad K, Zeraati H, Hosseini M, Naieni KH. Survival analysis of patients with gastric cancer undergoing surgery at the iran cancer institute: a method based on multi-state models. Asian Pac J Cancer Prev 2013;14:6369-73. doi: 10.7314/apjcp.2013.14.11.6369.

5. Roshanaei G, Sadighi S, Safari M, Faradmal J. Estimated survival time in gastric cancer patients and its associated factors. Koomesh 2012;14:47-54.

6. Cheon S, Rha S, Jeung HC, Im CK, Kim S, Kim H, et al. Survival benefit of combined curative resection of the stomach (D2 resection) and liver in gastric cancer patients with liver metastases. Ann Oncol 2008;19:1146-53. doi: 10.1093/annonc/mdn026.

7. Putter $\mathrm{H}$, van der Hage J, de Bock GH, Elgalta R, van de Velde CJ. Estimation and prediction in a multi-state model for breast cancer. Biom $J$ 2006;48:366-80. doi: 10.1002/ bimj.200510218.

8. Saint-Pierre P. Multi-state models and cost-effectiveness analysis. Journal de gestion et d'économie médicales 2016;34:133-44.

9. Hajihosseini M, Amini P, Shahdoust M, Faradmal J, Sadeghyfar M, Sedighi-Pashaki A. Application of lognormal parametric model in disability structure to predict metastasis and death due to breast cancer. Koomesh 2016;18:95-101.

10. Meier-Hirmer C, Schumacher M. Multi-state model for studying an intermediate event using time-dependent covariates: application to breast cancer. BMC Med Res Methodol 2013;13:80. doi: 10.1186/1471-2288-13-80.

11. von Cube M, Schumacher M, Wolkewitz M. Basic parametric analysis for a multi-state model in hospital epidemiology. BMC Med Res Methodol 2017;17:111. doi: 10.1186/s12874017-0379-4.

12. Hajihosseini M, Faradmal J, Sadighi-Pashaki A. Survival analysis of breast cancer patients after surgery with an intermediate event: application of illness-death model. Iran J Public Health 2015;44:1677-84.

13. Posch F, Riedl J, Reitter EM, Kaider A, Zielinski C, Pabinger I, et al. Hypercoagulabilty, venous thromboembolism, and death in patients with cancer. Thromb Haemost 2016;115:817-26.

14. Klein JP, Shu Y. Multi-state models for bone marrow transplantation studies. Stat Methods Med Res 2002;11:11739. doi: 10.1191/0962280202sm277ra.

15. Meira-Machado L, de Uña-Álvarez J, Cadarso-Suarez C, Andersen PK. Multi-state models for the analysis of timeto-event data. Stat Methods Med Res 2009;18:195-222. doi: 10.1177/0962280208092301.

16. Roshanaei G, Ghannad MS, Jafarabadi MA, Faradmal J, Sadighi S. Prognostic impact of risk factors in patients with gastric cancer in Iran. Asian Pac J Cancer Prev 2011;12:3005-8.

17. Allemani C, Weir HK, Carreira H, Harewood R, Spika D, Wang XS, et al. Global surveillance of cancer survival 19952009: analysis of individual data for 25676887 patients from 279 population-based registries in 67 countries $(\mathrm{CON}$ CORD-2). Lancet 2015;385:977-1010. doi: 10.1016/S01406736(14)62038-9.

18. Maroufizadeh S, Hajizadeh E, Baghestani AR, Fatemi SR. Multivariate analysis of prognostic factors in gastric cancer patients using additive hazards regression models. Asian Pac J Cancer Prev 2011;12:1697-702.

19. Posch F, Leitner L, Bergovec M, Bezan A, Stotz M, Gerger A, et al. Can multistate modeling of local recurrence, distant metastasis, and death improve the prediction of outcome in patients with soft tissue sarcomas? Clin Orthop Relat Res 2017;475:1427-35. doi: 10.1007/s11999-017-5232-x.

20. Li X, Wang W, Ruan C, Wang Y, Wang H, Liang X, et al. Agespecific impact on the survival of gastric cancer patients with distant metastasis: an analysis of SEER database. Oncotarget 2017;8:97090-100. doi: 10.18632/oncotarget.21350. 
21. Al-Refaie WB, Hu CY, Pisters PW, Chang GJ. Gastric adenocarcinoma in young patients: a population-based appraisal. Ann Surg Oncol 2011;18:2800-7. doi: 10.1245/s10434-0111647-x.

22. Yang D, Hendifar A, Lenz C, Togawa K, Lenz F, Lurje G, et al. Survival of metastatic gastric cancer: Significance of age, sex and race/ethnicity. J Gastrointest Oncol 2011;2:77-84. doi: 10.3978/j.issn.2078-6891.2010.025.

23. Samadi F, Babaei M, Sadjadi A, Yazdanbod A, Fallah M, Nouraie M, et al. Survival rate of gastric and esophageal cancers in Ardabil province, North-West of Iran. Arch Iran Med 2007;10:32-7.

24. Sitarz R, Skierucha M, Mielko J, Offerhaus GJA, Maciejewski R, Polkowski WP. Gastric cancer: epidemiology, prevention, classification, and treatment. Cancer Manag Res 2018;10:239-48. doi: 10.2147/CMAR.S149619.

25. Baba H, Kuwabara K, Ishiguro T, Kumamoto K, Kumagai Y, Ishibashi K, et al. Prognostic factors for stage IV gastric cancer. Int Surg 2013;98:181-7. doi: 10.9738/INTSURGD-12-00027.1.

26. Minami Y, Kanemura S, Oikawa T, Suzuki S, Hasegawa Y, Miura K, et al. Associations of cigarette smoking and alcohol drinking with stomach cancer survival: A prospective patient cohort study in Japan. Int $J$ Cancer 2018;143:1072-85. doi: 10.1002/ijc.31408.

27. Han MA, Kim YW, Choi IJ, Oh MG, Kim CG, Lee JY, et al. Association of Smoking History with Cancer Recurrence and Survival in Stage III-IV Male Gastric Cancer Patients. Cancer Epidemiol Biomarkers Prev 2013;22:1805-12. doi: 10.1158/1055-9965.EPI-13-0385.

28. Yatsuya H, Toyoshima H, Mizoue T, Kondo T, Tamakoshi K, Hori Y, et al. Family history and the risk of stomach cancer death in Japan: differences by age and gender. Int J Cancer 2002;97:688-94. doi: 10.1002/ijc.10101.

29. Ghadimi M, Mahmoodi M, Mohammad K, Zeraati H, Rasouli M, Sheikhfathollahi M. Family history of the cancer on the survival of the patients with gastrointestinal cancer in northern Iran, using frailty models. BMC Gastroenterol 2011;11:104. doi: 10.1186/1471-230X-11-104

30. Gong EJ, Ahn JY, Jung HY, Lim H, Choi KS, Lee JH, et al. Risk factors and clinical outcomes of gastric cancer identified by screening endoscopy: a case-control study. $J$ Gastroenterol Hepatol 2014;29:301-9. doi: 10.1111/jgh.12387.

31. Shakeri R, Malekzadeh R, Etemadi A, Nasrollahzadeh D, Aghcheli K, Sotoudeh M, et al. Opium: an emerging risk factor for gastric adenocarcinoma. Int $J$ Cancer 2013;133:455-61. doi: 10.1002/ijc.28018.

32. Naghibzadeh Tahami A, Khanjani N, Yazdi Feyzabadi V, Varzandeh M, Haghdoost AA. Opium as a risk factor for upper gastrointestinal cancers: a population-based casecontrol study in Iran. Arch Iran Med 2014;17:2-6.

33. Nikaeen R, Khalilian A. Bahrampour A. Determining the Effective Factors on Gastric Cancer Using Frailty Model in South-East and North of Iran. Iran J Health Sci 2017;5:35-48. 